Check for updates

London

Cite this as: $B M J$ 2020;371:m4695 http://dx.doi.org/10.1136/bmj.m4695 Published: 01 December 2020

\title{
Covid-19: Asymptomatic cases may not be infectious, Wuhan study indicates
}

Shaun Griffin

A mass screening programme of more than 10 million residents of Wuhan, China, performed after SARS-CoV-2 was brought under control, has identified 300 asymptomatic cases of covid-19, none of which was infectious.

The findings cannot be extrapolated to countries where outbreaks have not been brought under control successfully, said the authors of the report, which was published in Nature Communications. ${ }^{1}$

The researchers conducted a screening programme using PCR testing for viral RNA among the 10 million participants who were aged between 10 and 89 . Trained staff interviewed participants on their history of covid-19. Asymptomatic positive cases were those who had a positive result on screening with neither a history of covid-19 diagnosis nor any clinical symptoms at the time of the nucleic acid testing. The researchers found no "viable virus" in cultures from asymptomatic samples.

The asymptomatic positive rate was lowest in participants aged under 17 and highest in those over 6o. Further swab testing of 1174 close contacts of the 300 asymptomatic positive cases were all negative. The study population included 34424 people with a history of covid-19, 107 of whom (0.310\%) had been re-infected.

\section{Findings not generally applicable}

The researchers said that their findings did not show that the virus couldn't be passed on by asymptomatic carriers, and they didn't suggest that their findings were generalisable.

They said that strict measures-such as mask wearing, hand washing, social distancing, and lockdown-were successful in reducing the virulence of SARS-CoV-2 in Wuhan and that asymptomatic people in Wuhan may have low viral loads. This means that the finding cannot be applied to countries where outbreaks have not been successfully brought under control.

Fujian Song, from UEA's Norwich Medical School, who collaborated with colleagues in Wuhan on the research, said: "The asymptomatic cases identified in the screening programme were truly asymptomatic, as none of them showed clinical symptoms before or during their follow-up isolation.” But, he added, "there is plenty of evidence elsewhere showing that people infected with covid-19 may be temporarily asymptomatic and infectious, before going on to develop symptoms.”

Using antibody testing, the researchers found that almost two thirds of the asymptomatic cases had previously had covid-19. "With the centralised isolation and treatment of all covid-19 cases during the lockdown period in Wuhan, the risk of residents being infected in the community has been greatly reduced. When susceptible residents are exposed to a low dose of virus, they may tend to be asymptomatic as a result of their own immunity," wrote the authors.

Song said, "It is very important to say that these asymptomatic cases were identified shortly after the relaxation of a very stringent lockdown in Wuhan that lasted more than 70 days. By then, the epidemic in Wuhan had been effectively brought under control. It is too early to be complacent, because of the existence of asymptomatic positive cases and high level of susceptibility in residents in Wuhan."

Noting that mask wearing remains common in public places, he added that this and other public health measures, such as safe social distancing, should be sustained in Wuhan to control transmission, noting that "vulnerable populations with weakened immunity or comorbidities, or both, should continue to be appropriately shielded."

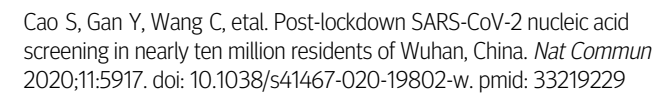

Cao S, Gan Y, Wang C, etal. Post-lockdown SARS-CoV-2 nucleic acid screening in nearly ten million residents of Wuhan, China. Nat Commun 2020;11:5917. doi: 10.1038/s41467-020-19802-w. pmid: 33219229

This article is made freely available for use in accordance with BMJ's website terms and conditions for the duration of the covid-19 pandemic or until otherwise determined by BMJ. You may use, download and print the article for any lawful, non-commercial purpose (including text and data mining) provided that all copyright notices and trade marks are retained. 